\title{
2 | 2021
}

75. Jahrgang

21. Januar 2021

S. $65-128$

PVSt 4954
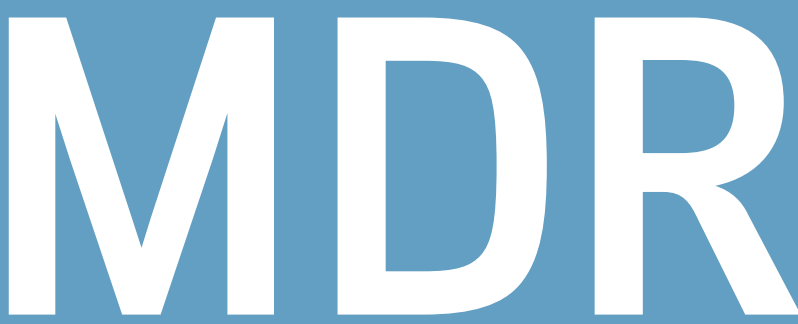

\section{Monatsschrift für Deutsches Recht}

Zeitschrift für Zivil- und Zivilverfahrensrecht

\section{mdr-recht.de}

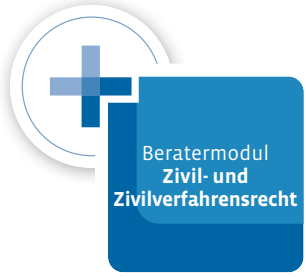

Profitieren Sie von Ihrer ONLINE-DATENBANK
Aufsätze > Hans Christian Schwenker / Markus Wessel - HOAI 2021: Die wich-

tigsten Änderungen der Honorar- und Gebührenordnung für Architek-

ten und Ingenieure

Robert Harsch - Gebühren: Außergerichtliche Anwaltskosten im Mietrecht

Mark Seibel - Schadensersatz: Das wiederholte Märchen des VII. Zivilsenats des BGH von den „Besonderheiten des Werkvertragsrechts”

Prozessrecht aktiv > Selbständiges Beweisverfahren: Kostentragung bei Rücknahme des Antrages (BGH, Beschl. v. 20.10.2020 - VI ZB 28/20, MDR 2021, 126) Oliver Seggewiße

Streitwertfestsetzung: Beschwerde gegen die Ablehnung eines Antrags auf Änderung (OLG Bremen, Beschl. v. 7.9.2020 - 1 W 20/20, MDR 2020, 1470) Peter Fölsch

Beweisrecht: Indizielle Bedeutung eines Arztberichtes (OLG Jena, Urt. v. 26.6.2020 - 4 U 279/19, MDR 2020, 1399) Hans-Willi Laumen

Rechtsprechung > Vertragsrecht: Anwaltsvertrag als Fernabsatzgeschäft (BGH, Urt. v. 19.11.2020 - IX ZR 133/19)

Haftungsrecht: Warnhinweis auf Ärzteportal bei Verdacht auf manipulierte Bewertungen (OLG Frankfurt, Urt. v. 19.11.2020 - 16 W 37/20)

Arbeitsrecht: Urlaubsgewährung bei fristloser Kündigung (BAG, Urt. v. 25.8.2020 - 9 AZR 612/19)

Bankrecht: Wirksamkeit einer Widerrufsbelehrung bei fehlenden Zwischenüberschriften in Verbraucherdarlehen (BGH, Urt. v. 10.11.2020 XI ZR 426/19)

Verfahrensrecht: Pflicht des Berufungsgerichts zur erneuten Vernehmung von Zeugen (BGH, Beschl. v. 21.10.2020 - XII ZR 114/19) 
